\title{
A comparative study on spontaneous whelping, assisted whelping and emergency caesarean section in canines
}

\begin{abstract}
A total of 26 bitches presented to University Veterinary Hospital Kokkalai belonging to 10 different canine breeds where included in the study to compare between spontaneous whelping(SW) assisted whelping(AW) and emergency C- section(EC) out of which 21 bitches were presented with difficulty in whelping and 4 were normal whelping. Mean age of the bitches in AW, EC and SW was $2.38 \pm 0.23$ years, $2.35 \pm 0.27$ and $2 \pm 0.15$ years respectively. Out of 21 bitches presented with difficulty in whelping, 12 bitches(57\%) were primiparous. Gestational length calculated from the last breeding date was $61.11 \pm 0.73$ days $61.13 \pm 0.61$ days and $61 \pm 0.71$ days in $\mathrm{AW}$, EC and SW respectively. Gestational age of the foetuses determined by ultrasonography in $\mathrm{AW}$ and $\mathrm{EC}$ ranged from 57 to $62(60.5 \pm 0.99)$ days and 58 to $62(60.2 \pm 0.73)$ days respectively. Heart rate of the foetuses determined by ultrasonography in AW and EC ranged from $171 \mathrm{bpm}$ to $267(201.55 \pm 10.49) \mathrm{bpm}$ and $157 \mathrm{bpm}$ to $240 \mathrm{bpm}(177.30 \pm 9.26)$ respectively. Out of 21 bitches presented with difficulty in whelping, 6(28.6 per cent) whelpings were managed with medical therapy using ecbolics, 7(33.3 per cent) whelpings were managed with medical therapy along with manipulative delivery and 8 (38 percent) whelpings were managed with emergency Caesarean section.
\end{abstract}

Keywords: dystocia, emergency caesarean section, spontaneous whelping, ultrasonography, gestational age
Volume 5 Issue I - 2017

\author{
Karthik V Kuttan, Metilda Joseph \\ Department of Animal Reproduction, Gynaecology and \\ Obstetrics, College of Veterinary and Animal Sciences, India
}

Correspondence: Karthik V Kuttan, Post graduate scholar, Department of Animal Reproduction Gynaecology and Obstetrics, College of Veterinary and Animal Sciences, Mannuthy, Kerela, India, 68065I, Tel 9400528255 .

Email 88kartikvk@gmail.com

Received: November 09, 2016 | Published: February 08, 2017

\section{Introduction}

Canine pregnancies are unique among veterinary domestic species as the whelping process is longer in duration and the neonates are highly influenced by the environmental factors. Stage 1 labor in bitches began with rhythmic uterine contractions and progressive cervical dilatation. Duration was normally 6 to 12 hours but could extend upto 24hours in primiparous bitches. ${ }^{1}$ The mean intervals between the birth of two successive puppies ranged between 30 and 60 minutes in most breeds. ${ }^{2}$ Gestational length in the bitch is about 57 to 72 days with an average of 65 days, when breeding dates were taken into consideration ${ }^{3}$ and whelping could occur anywhere between $63 \pm 7$ days from the day of breeding. ${ }^{4}$

Dystocia is defined as the inability to expel the foetus through the birth canal without assistance and it can be of maternal or foetal origin. Among reproductive disorders, about 12percent were of canine dystocia and maximum percent of dystocia affected bitches $(85 \%)$ had litter size of four pups including large breeds and that was suggestive of dystocia due to primary and secondary uterine inertia. ${ }^{5}$

Maximum percentage of dystocia affected bitches( 85 per cent) had litter size of 4 pups including large breeds ${ }^{5}$ and 75.3 percent of the dystocia is of maternal origin, mainly due to inertia, while that of fetal origin accounted for about 24.7 percent mainly resulting from malpresentations/malorientations. ${ }^{6}$ Whelping begin normally in secondary inertia but the uterine contractions stops after sometime and the most common reason for secondary uterine inertia is the obstruction of birth canal. ${ }^{7}$

Miniature and small breeds showed a significant higher incidence for dystocia accounting for 26 percent and 33.4 percent respectively. ${ }^{8}$ The incidence of dystocia in canines was considered to be highest in bitches aged 2-4years. ${ }^{6}$ The highest number of dystocia were recorded in primiparous bitches. ${ }^{9}$

\section{Materials and methods}

Twenty six apparently healthy pregnant bitches between one to five years of age with physical and behavioural changes associated with whelping presented at University Veterinary Hospital, Kokkalai, India were subjected to clinico-gynaecological examination based on history. Gestational age(GA) was calculated from the last breeding date and also by measurement of head diameter(HD) using real time B-mode ultrasonography using the formula $\mathrm{GA}( \pm 3$ days $)=$ $20+(15 \times \mathrm{HD}) .{ }^{10}$

The viability of the foetus was assessed based on foetal movements and heart rate at the time of ultrasonography. Clinical interventions such as lubrication with obstetrical cream, feathering, traction by hand/whelping forceps were performed whenever necessary. In case of uterine inertia, 10 percent Calcium gluconate $\left(\right.$ Calcium-Sandoz ${ }^{\mathbb{R}}$ ) solution at the rate of $0.2 \mathrm{ml} / \mathrm{kg}$ was administered along with 25 percent Dextrose(DEXTROSE), $5-25 \mathrm{ml}$ intravenously over a period of 2-5minutes. Oxytocin(Pitocin ${ }^{\circledR}$ ) was administered at the dose rate of $0.1-0.5 \mathrm{IU} / \mathrm{kg}$ intramuscularly and repeated after $60-90$ minutes whenever necessary. Emergency Caesarean section was carried out in those cases which did not respond to medical management or manipulative delivery.

Total duration of whelping and time interval between the expulsion of two puppies/expulsion phase length from whelping cases other than EC were recorded. Records were enclosed in a data base and statistically analyzed using SPSS version. 21 statistics software package. 


\section{Results}

\section{Detailed signalment and anamnensis}

A total of 26 bitches belonging to 10 different canine breeds where included in the study, out of which 13 bitches $(50 \%)$ belonged to small breed group $(<10$ kilogram $)$. The overall mean age of the bitches included in the study was $2.271 \pm 0.15$ years. The mean age of the bitches in AW, EC and SW was $2.38 \pm 0.23,2.35 \pm 0.27$ and $2.00 \pm 0.29$ years respectively (Table 1 ).

Out of 21 bitches presented with difficulty in whelping, the parity ranged from 0 to 2 with a mean of $0.63 \pm 0.13$ and 12 out of $21(57 \%)$ bitches were primiparous. Two out of $21(9.5 \%)$ bitches had previous history of dystocia. Gestational length calculated from the last breeding date ranged from 57 to 65days in AW group with a mean of $61.11 \pm 0.73$ days, in EC it ranged from 58 to 63 days with a mean of $61.13 \pm 0.61$ days and in SW it ranged from 59 to 63days with a mean of $61 \pm 0.71$ days.

\section{Details of ultrasonographic examination}

Gestational age of the foetuses determined by ultrasonography ranged from 57 to 62 days with a mean of $60.5 \pm 0.99$ days in AW group and in EC it ranged from 58 to 62 days with a mean of $60.2 \pm 0.73$ days. Mean biparietal diameter of the foetuses was $2.68 \pm .05 \mathrm{~cm}$ in AW group and $2.69 \pm .06 \mathrm{~cm}$ in EC group. The mean heart rate of the foetuses determined by ultrasonography was $201.55 \pm 10.49$ (171 to 267 )bpm in
AW group and in EC group it was $177.30 \pm 9.26$ (157 to 240$) \mathrm{bpm}$.

\section{Response to medical management}

Out of 21 bitches presented with difficulty in whelping, 28.6 percent, 33.4 percent and 38 percent whelpings were managed with medical therapy using ecbolics, medical therapy along with manipulative delivery and emergency Caesarean section respectively.

\section{Litter size, expulsion phase length/inter-pup interval} and total duration of whelping

Mean litter size in AW group was $4.07 \pm 0.48$, in EC it was $3.31 \pm 0.42$ and in SW it was $5.89 \pm 0.98$. Mean litter size was positively correlated with average body weight of the $\operatorname{bitch}(\mathrm{P}<0.01)$, average body weight of the puppy $(\mathrm{P}<0.01)$ and negatively correlated to average expulsion time $(\mathrm{P}<0.05)($ Table 2$)$. Expulsion phase length in AW group ranged from $45 \mathrm{~min}$ to $360 \mathrm{~min}$ with a mean of $139.62 \pm 24.7 \mathrm{~min}$ and in SW group it ranged from $30 \mathrm{~min}$ to $60 \mathrm{~min}$ with a mean of $48.33 \pm 4.17 \mathrm{~min}$. Total duration of whelping in AW ranged from $180 \mathrm{~min}$ to $1500 \mathrm{~min}$ with a mean of $401.54 \pm 94.52 \mathrm{~min}$ and in $\mathrm{SW}$ it ranged from $145 \mathrm{~min}$ to $520 \mathrm{~min}$ with a mean of $236.88 \pm 46.64 \mathrm{~min}$.

Out of 22 puppies evaluated in SW and AW, 86.36 percent puppies were born with intact amnion. In AW group, 76.90 percent puppies were in anterior presentation and 20.10 percent in posterior presentation. In SW group, 77.77 percent were in anterior presentation and 33.33 percent were in posterior presentation.

Table I Detailed signalment and anamnensis of dystocic and eutocic bitches

\begin{tabular}{|c|c|c|c|c|c|}
\hline $\begin{array}{l}\text { Nature of } \\
\text { whelping }\end{array}$ & $\begin{array}{l}\text { Number of } \\
\text { bitches(n) }\end{array}$ & $\begin{array}{l}\text { Age(years) } \\
\text { (Mean } \pm \text { SE) }\end{array}$ & $\begin{array}{l}\text { Parity } \\
\text { (Mean } \pm \text { SE) }\end{array}$ & $\begin{array}{l}\text { Body weight(Kg) } \\
\text { (Mean士SE) }\end{array}$ & $\begin{array}{l}\text { Gestational length(days) } \\
\text { (Mean } \pm \text { SE) }\end{array}$ \\
\hline AW & 13 & $2.38 \pm 0.23$ & $0.69 \pm 0.23$ & $|5.67 \pm 3.5|$ & $61.11 \pm 0.73$ \\
\hline EC & 8 & $2.35 \pm 0.27$ & $0.6 I \pm 0.24$ & $13.32 \pm 1.50$ & $61.13 \pm 0.61$ \\
\hline SW & 5 & $2.00 \pm 0.29$ & $0.55 \pm 0.18$ & $20.17 \pm 5.32$ & $61 \pm 0.71$ \\
\hline Total & 26 & $2.27 \pm 0.15$ & $0.63 \pm 0.13$ & $15.96 \pm 1.96$ & $61.07 \pm 0.40$ \\
\hline
\end{tabular}

AW, assisted whelping; EC, emergency caesarean section; SW, spontaneous whelping

Table 2 Litter size, expulsion phase length/inter-pup interval and total duration of whelping in bitches

\begin{tabular}{lllll}
\hline $\begin{array}{l}\text { Type of } \\
\text { whelping }\end{array}$ & $\begin{array}{l}\text { Number of } \\
\text { bitches }(\mathbf{n})\end{array}$ & $\begin{array}{l}\text { Litter size } \\
(\text { Mean } \pm \text { SE) }\end{array}$ & $\begin{array}{l}\text { Expulsion phase length (min) } \\
(\text { Mean } \pm S E)\end{array}$ & $\begin{array}{l}\text { Total duration of whelping (min) } \\
(\text { Mean } \pm S E)\end{array}$ \\
\hline AW & 13 & $4.07 \pm 0.48$ & $139.62 \pm 24.7$ & $401.54 \pm 94.52$ \\
SW & 5 & $5.89 \pm 0.98$ & $48.33 \pm 4.17$ & $236.88 \pm 46.64$ \\
EC & 8 & $3.31 \pm 0.42$ & NA & NA \\
Total & 26 & $4.26 \pm 0.38$ & $102.273 \pm 17.45$ & $338.81 \pm 62.67$ \\
\hline
\end{tabular}

AW, assisted whelping; EC, emergency caesarean section; SW, spontaneous whelping

\section{Discussion}

Out of 26 bitches considered in the study, 13 bitches $(50 \%)$ belonged to small breed group $(<10$ kilogram) which is in agreement with earlier studies. ${ }^{8,11}$ The present study agrees with the findings of Oluwatoyin $\mathrm{AO} \&$ Fayemi $\mathrm{OE}^{9}$ who found that the highest number of dystocia were observed in primiparous bitches which might be due to mating them too early in life. The mean age of the bitches in AW and EC was $2.38 \pm 0.23$ and $2.35 \pm 0.27$ years respectively which is in agreement with earlier studies. ${ }^{12,13}$ Gestational length calculated from the last breeding date is in agreement with the observations of Johnson CA \& Christiansen $\mathrm{IJ}^{4,11}$ who opined that the whelping could occur anywhere between 57 and 72 days after breeding. Gestational age of the foetuses and average biparietal diameter and heart rate of foetuses is in accordance with Nyland TG, Beccaglia M, England GCW. ${ }^{10,14,15}$ In case of bitches with dystocia, 33.3 percent whelpings were managed with medical therapy along with manipulative delivery which is in accordance with Oluwatoyin AO \& Fayemi OE. ${ }^{9}$ 
Inter-pup interval was highest in AW which is in accordance with the views of Johnston SD, Naaktgeboren C \& Lopate C. ${ }^{1,2,16}$ The increase in inter-pup interval in AW whelping group could be due to exhaustion of the bitch due to ineffective uterine contractions, foetal disproportion or foetal presentation that caused dystocia as stated by Gill MA. ${ }^{17}$

\section{Conclusion}

Dystocia was more common in primiparous small dog breeds. The gestational length in bitches ranged from 57 to 72 days. In bitches, 33.3 percent dystocia were managed with medical therapy along with manipulative delivery. Mean litter size was positively correlated with average body weight of the bitch, average body weight of the puppy and negatively correlated to average expulsion time.

\section{Acknowledgements}

This work is supported and funded by Kerala Veterinary and Animal Sciences University, Pookot.

\section{Conflict of interest}

Author declares that there is no conflict of interest.

\section{References}

1. Johnston SD, Kustritz MVR MV, Olson PNS. Canine and Feline Theriogenology. 2nd ed. Philadelphia: Saunders; 2001. 867p.

2. Naaktgeboren C, Verne MA, van der Weijden GC. Parturition in the dog. Naarden, Netherlands: Strengholt's Publishers; 2002. p. 540.

3. Concannon PW, Whaley S, Lein D, et al. Canine gestation length: variation related to time of mating and fertile life of sperm. Am J Vet Res. 1983;44(10):1819-1821.

4. Johnson CA. Pregnancy management in the bitch. Theriogenology. 2008;70(9):1412-1417.
5. Ramsingh L, Rao KS, Muralimohan K. The Reproductive disorders and dystocia in canines. IOSR Journal of Pharmacy. 2013;3(1):15-16.

6. Darvelid AW, Linde-Forsberg C. Dystocia in the bitch: A retrospective study of 182 cases. J Small Anim Pract. 1994;35(8):402-407.

7. Linde-Forsberg C. Abnormalities in pregnancy, parturition and peri parturient period. In: Ettinger SJ, Feldman EC, editors. Textbook of Veterinary Internal Medicine. 5th ed. Philadelphia: Saunders; 2005. p. $1655-1567$.

8. Munnich A, Kuchenmeister U. Causes, diagnosis and therapy in neonatal puppies in the first days of life: Cornerstones of practical approach. Reprod Domest Anim. 2008;49(Suppl 2):64-74.

9. Oluwatoyin AO, Fayemi OE. A Survey on Cases of Dystocia in Bitch at South-Western Nigeria. Global Veterinaria. 2011;6(1):97-100.

10. Nyland TG, Mattoon JS. Small animal diagnostic ultrasound. 3rd ed. Philadelphia: WB Saunders; 2015. p. 1800.

11. Christiansen IJ. Reproduction in the dog and cat. London: Bailliere Tindall; 1984. p. 230.

12. Bennur S, Krishnaswamy A, Honnappa TG. Studies on causes and treatment of dystocia in canines. Indian J Anim Reprod. 2001;22:184-186.

13. Gaudet DA (1985) Retrospective study of 128 cases of canine dystocia. J Am Ani Hosp Assoc. 1985;21:813-818.

14. Beccaglia M, Luvoni GC. Prediction of Parturition in Dogs and Cats: Accuracy at Different Gestational Ages. Reprod Domest Anim. 2012;47(Suppl 6):194-196.

15. England GCW. Ultrasonographic assessment of abnormal pregnancy. Vet Clin North Am Small Anim Pract. 1998;28(4):849-868.

16. Lopate C. Reproductive Physiology of Canine Pregnancy and Parturition and Conditions of the Periparturient Period. Management of pregnant and neonatal dogs, cats and exotic pets. 2nd ed. 2012:25-42.

17. Gill MA. Perinatal and late neonatal mortality in the dog. PhD. thesis, The University of Sidney. 2007. 98p. 